\title{
Innovation management in high school visual communications: from heraldry to animation
}

\author{
Svetlana Shlyakhova, Yulia Lektorova*, and Natalia Bolshakova \\ PNRPU, 29, Komsomolsky prospect, Perm, 614990, Russia
}

\begin{abstract}
The article considers problems of innovative practices of building visual communication in higher education. In the theoretical part of the article, the authors' model of university brand identity and a model of university logo identity are proposed. The research part presents the initial analysis results of the graphic design of university logos and the data on 80 logos comparative analysis, performed according to the color, font, symbol, shape criteria. Based on the results of the study, comparative analysis of the identified trends in formation of logos of Russian and foreign universities was conducted.
\end{abstract}

\section{Introduction}

The key task of higher school modern visual communications remains search for tools and solutions that ensure recognition and loyalty among both external and internal audiences, regardless of the university's position in the international ranking, its history and location. The arsenal of possible directions of visual communication in modern conditions includes mechanisms of brand innovation, among which there should be considered methods of developing and restyling corporate identity (logos), aimed at creating and maintaining a holistic image of higher education in general public mind.

Foreign researchers understand brand innovation as the degree to which consumers perceive brands as capable of offering new and useful solutions to their needs [1,2]. From our point of view, this approach, which implies, first of all, the degree of innovativeness of the product it offers, with which the consumer associates it with, cannot be exhaustive. Brand innovation should also be understood as the degree of innovation of the very nature of brand communication with consumers, including visual communication.

Today, visual communication is one of the main components of modern mass media, transforming any content into visual codes. During the period of active development of electronic digital technologies, visual communications resemble the process of transferring information "through visual language (images, signs, pictures, typography, infographics, etc.), on the one hand, and visual perception (organs of vision, psychology of perception, etc.) on the other hand" [3].

If we proceed from the statement of A. Berger that the purpose of any visual communication is to create an image [4], and the image remains the main acting agent of influence on consciousness of the target audience, we

\footnotetext{
Corresponding author: Lektorova2015@yandex.ru
}

can assume that innovations in visual communication in the academic environment and beyond it include modern trends in graphic design of logos.

In the language of professionals, graphic design is a visual display of any information about a specific object by applying an image to a medium using artistic techniques. Targeted at the mass consumer, such art and design activities include various illustrations, fonts, lettering, design of packaging, buildings, classrooms, laboratories and much more.

Taking into account the behavior of the main target audiences of corporate communications (both Russian and foreign), higher schools are testing unique corporate styles that identify originality of each educational unit in the digital media space (on websites, in social networks) and in the context of off-line contacts (on letterheads, souvenirs, advertising modules).

In visual representation of universities today, there is a clear movement from the coat of arms (the insignia of its owner, drawn up according to the rules of heraldry, must be on the heraldic shield) and the emblem (concepts, ideas, etc. in the form of a symbolic image) to the logo (trademark, graphic image, embodying and representing the brand) of the university.

If coats of arms and emblems tend to be academic, traditional, have long history, then logos are associated with dynamism, modernity, branding, marketing and advertising. It is also obvious that there is a clash of ideas about the university as an educational and scientific institution or as a business corporation [5].

In real practice of visual communication, the university image is not terminologically defined: the terms coat of arms, emblem, symbol and logo are often used as synonyms. Often the university coat of arms, freed from some details, acts as a logo.

The logo of any organization is a reflection of its essence, which it individualizes. "It is equally important for a logo to be recognizable and readable ... as a rule, 
people can only catch a glimpse of the logo, and often from a great distance. In such a situation, the main thing is recognition, not ease of reading " [6]. On this basis, most researchers focus on logo design that integrates recognizable characters, shapes, fonts, and colors.

The entire set of basic components of visual communication is included in the higher school brand identity system, along with functional advantages, emotional benefits, consumer values, the uniqueness of the university and of its educational service and the higher school mission.

Based on the existing models of brand identity [7], we propose a model of university brand identity, taking the pyramid model as a basis:

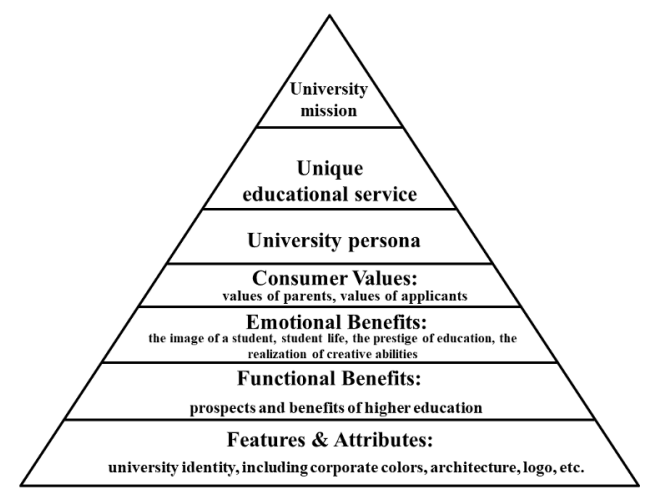

Figure 1. University brand identity model.

In this model, the logo as an element of attributes (identity, i.e. visual communication) "cements" and acts as the "foundation" of the higher school identity.

Identity of the university brand logo is built from three aspects: individuality, positioning, essence. Such aspects as individuality and positioning of the university brand logo have specific features.

Individuality of a university brand includes three elements: visual components (color, symbol, font), modernity, and memorability.

Positioning of the university brand includes reflection of three characteristic features in the logo: the main brand values (history and specificity of the university), territory (location of the university), mission, and the university motto.

Effective communication of the essence of the brand to the consumer is a logical combination of correct reflection of the characteristic features of positioning and brand personality. Based on the above, below is a model of university logo identity:

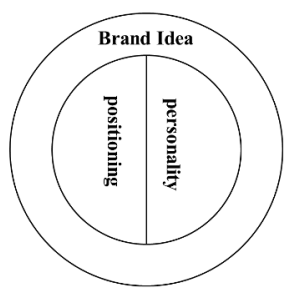

Figure 2. Brand identity model of the higher school logo
A logo as a visual metaphor is a sign system consisting of visual and semantic categories. The visual component is a sign with specific structural elements (font, symbol, shape) that form the external shape of the logo.

The semantic component is a culture sign that conveys meaningful symbols and senses to target audiences. In the era of networked communication, visual communication in general and graphic logo design in particular must be adapted to electronic multimedia as well.

\section{Methods}

This study attempts to identify trends in the design and architecture of logos of Russian and foreign universities.

The research material was selected according to the rating of the university on the official websites of the universities. The logos of included in the Top-20 and not included in the top rankings of universities were analyzed. A total of 80 university logos were analyzed: 40 Russian and 40 foreign ones:

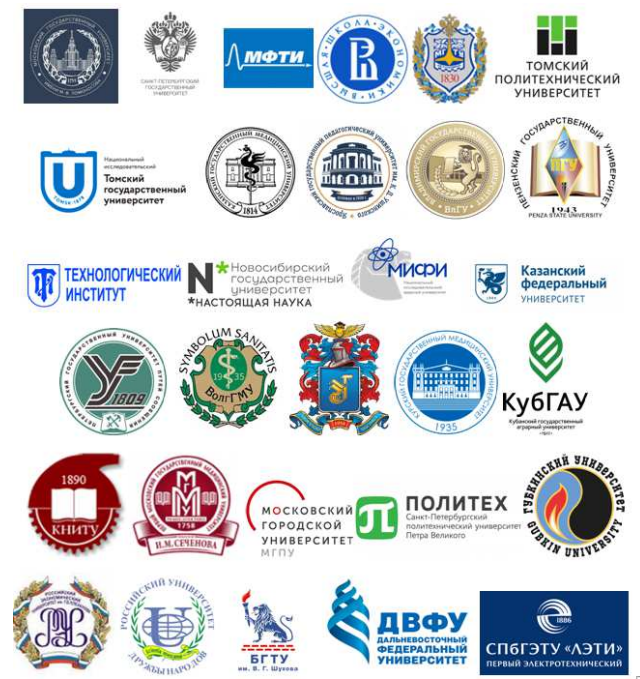

Figure 3. Logos of Russian universities

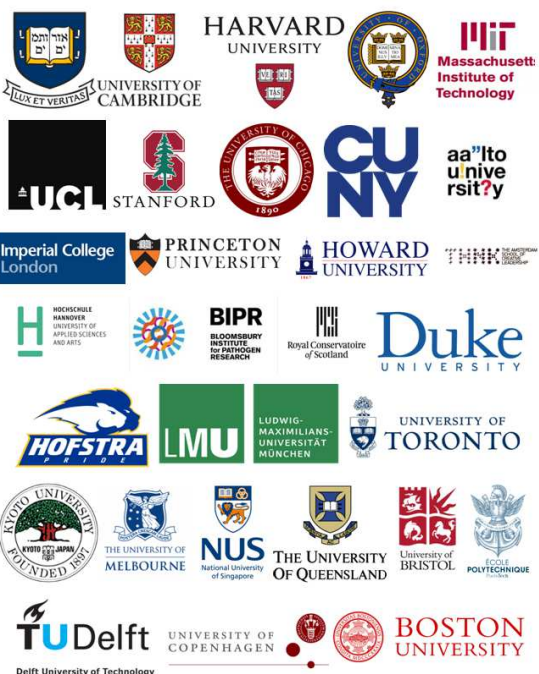

Figure 4. Logos of foreign universities 
Analysis and assessment of the brand identity of the logos of Russian and foreign universities are carried out according to the following method:

Initial analysis of logos according to the following criteria: logo evolution; verbal part, language; nonverbal part. When analyzing the non-verbal part, the following were taken into account: symbolism of the subject-material environment, emblems, color, geographic referencing.

Comparative analysis of logos of Russian and foreign universities according to the following criteria: quantity and quality of colors; adaptability of color for different media; font type; symbols (national, heraldic, industry, educational, natural, operational); the form; personality and modernity; availability of a brand / guidebook; brand positioning and values (year of university creation, continuity in brand evolution, reference to historically significant symbols, territory, training profiles).

Comparative analysis of the identified trends in the formation of logos of Russian and foreign universities, assessment of their brand identity.

Research time: 2019-2020

\section{Results}

The volume of the publication does not allow posting full analysis of the logos under study, so we will present some fragments of the initial logos analysis.

An example of the initial analysis of a foreign university logo (Harvard University):

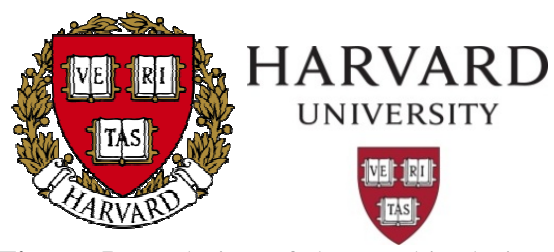

Figure 5. Evolution of the graphic design of the Harvard University logo (old and new university logos)

The analysis revealed the following results:

* logo evolution: yes

* verbal part, language: the word university (at present); in Latin truth

* non-verbal part:

- symbolism of the material environment, emblems: the symbol is the coat of arms - a shield with three open books, on the pages of which the truth is written; in the past, a wreath symbolizing knowledge and excellence. The signs of the shield and the open book symbolize strong and powerful education provided by the university;

- color: the crimson color is associated with love of freedom, it adjusts to a free atmosphere; USA.

- geo-referencing: the name of the city of Cambridge,

An example of the initial analysis of the logo of a Russian university (Tomsk Polytechnic University):

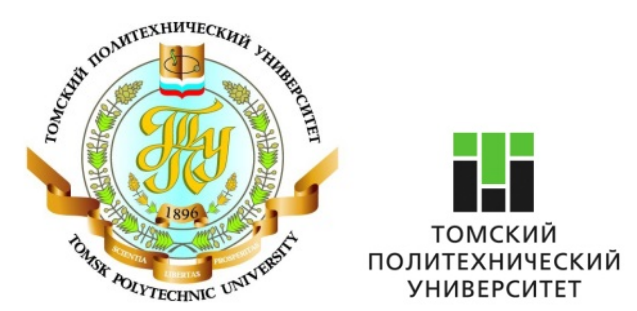

Figure 6. Evolution of the graphic design of the Tomsk Polytechnic University logo (old and new university logos)

The analysis revealed the following results:

* logo evolution: yes, the trend towards simplification

*verbal part, language: abbreviation and the university name in Russian

*non-verbal part:

- symbolism of the subject-matter environment, emblem: consists of blocks forming capital letters $\mathrm{T}$ and $\mathrm{P}$ (Tomsk Polytechnic) or T and U (Tomsk University); symbolizes multidimensionality, interconnection, harmonious coexistence of individual elements of the university: students, employees, graduates, structural units, departments, laboratories, centers, institutes. The square consists of six rectangular parts, which correspond to the six main directions of scientific development of this university. Continuity is only in abbreviation and green, which is the main color in all previous versions of the university logo.

- color: the green color of the letter "T" (Tomsk) is traditional for the university. This is the color of the natural environment from which man emerged. The black color of the letter "P" (Polytechnic) is technological, symbolizing modern engineering solutions. The combination of colors used in the logo indicates the basis of the university's scientific and educational activities: solving global problems of mankind through development of resource-efficient technologies.

- geo-referencing: the name of the city of Tomsk, Russia.

All the logos of Russian and foreign universities under study were analyzed and systematized in a similar way.

There are obviously two main styles in the university logos:

* heraldic (shields, ribbons, mottos in Latin, fittings, laurel crown, wide color palette, tightness of the visual range, etc.): the desire of the university to emphasize duration of its existence, prestige, fundamentality, tradition, etc.;

* minimalist (conciseness, simplicity, clarity, limited color palette, contrast, a lot of empty space, etc.): the desire of the university to emphasize modernity, dynamism, innovation, aspiration for the future, etc.

In the logos of foreign universities, striving for minimalism slightly dominates, in the logos of domestic universities - heraldic elements.

The main means of visual communication are the basic components of a logo graphic design - color, font, symbol. 
Color. The palette of university logos used is represented by a variety of color and compositional solutions.

According to designers, it is color that creates visual sensation and emotional impact in visual communication. The choice of the color palette should take into account coloristic preferences of the target audience and correlate with objective characteristics of the identified object.

Analysis of such a graphic component as color showed that the top foreign universities mostly have two types of logos - tricolor and bicolor (40\%), while the other universities are dominated by tricolor logos (33\%).

Top Russian universities most often have logos consisting of two colors (54\%), while other universities are dominated by one-color logos $(40 \%)$.

The adaptability of the main color is insufficient for all universities: in $80 \%$ of foreign universities, the logo color is not adapted for various media. In 52\% of Russian top universities the logo color is not adapted for media, in the rest $-60 \%$ of the logos.

The most common primary colors in foreign universities are blue, burgundy / red, black and white; the Russian universities have blue and white.

Analysis of the primary colors of the logos did not show significant differences between the top and other universities in Russia and abroad. There are no significant differences in the design of logos between Russian and foreign universities:

* dominant colors in university logos - blue, white (as the main color of the field), burgundy / red; foreign universities often have black;

* poor adaptation of logos to different media;

* prevalence of one- and two-color logos; in the logos of foreign universities, preference is often given to emblems in which there are more than three colors.

The dominance of blue, white and burgundy / red in the logos of universities can be associated with tinctures in heraldry (the name of paints and coatings of heraldic bodies).

Today, many universities use color coding for faculties and departments, assigning each its own color and an additional symbol (icon). This approach solves the problem of self-identification of university departments.

Font. Of particular importance is the font, which is considered the basis of graphic design, representing a certain style of characters, their general image and size. Fonts are conventionally divided into four main groups: serif fonts (antiqua), sans serif fonts (sans serifs), decorative fonts, and handwritten fonts. For each font, there are several types of styles, features of their image: normal, italic, bold and bold italic.

The variety of fonts used in university logos is an additional tool for visualizing information. When choosing an appropriate font, designers are guided by the basic requirements: harmony of proportions; simplicity and clarity; clarity and proportionality to ensure readability; "associativity" (grace - massiveness, rigor - liveliness, etc.); the purpose of the font (font readability, relevance) [8].

Analysis of the font showed that the most frequent font type for the best foreign universities is sans serif $(62 \%)$, for other universities - serif in the same proportion $(62 \%)$. The top Russian universities are dominated by serif $(70 \%)$, the rest have sans serif $(44 \%)$ and serif $(45 \%)$ in almost equal proportions.

The typeface gave almost the same results for all universities: the "normal" typeface dominates in the $\log 0$ of foreign $(60-80 \%)$ and domestic $(70-90 \%)$ universities.

Analysis of the logotype did not show significant differences between the top and other foreign and Russian universities. There are no significant differences in font between Russian and foreign universities:

* dominant fonts in university logos - serif and sans serif; at the top foreign universities sans serif prevails $(62 \%)$, at the top Russian universities - serif (70\%);

* "Normal" typeface dominates in the logos of foreign (60-80\%) and domestic (70-90\%) universities.

Symbolism. At the first stage, the analysis of visual semiotics in university logos was carried out on the basis of the classification of P.V. Demin, who identifies national, heraldic, natural, sectoral, educational, operational (figures, rectangles, ovals, triangles, lines, points and stars, etc.) symbolism [9]. We will also include state symbols as national symbols.

The analysis showed that the TOP 20 foreign universities are dominated by heraldic and operational (26\% each) symbols, but taking into account the fact that operational symbols are additional graphic elements of the logo, we can say that the dominant symbols of the best foreign universities are heraldic. Other foreign universities are dominated by industry (33\%) and educational $(27 \%)$ symbols.

Operational $(27 \%)$, heraldic and national-state $(23 \%$ each) symbols dominate in the logos of Russian universities. The rest of the universities have nationalstate $(23 \%)$ and industry (19\%) types of symbols.

Heraldic symbols are popular with top universities because the TOP-20 is occupied by the oldest universities in the world, and their logo since its foundation is usually a coat of arms, modernized to match the logo.

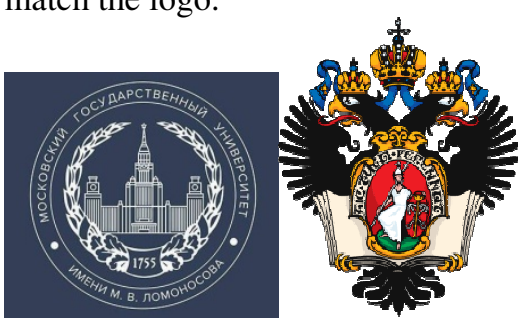

Figure 7. Logo and coat of arms of Moscow State University, St. Petersburg State University

The logo, which has a five-hundred-year history (University of Aberdeen), consists of four coats of arms: the coat of arms of Old Aberdeen (seat of King's College), the coat of arms of Bishop Elphinstone (founder of King's College), the coat of arms of Keith, 
the Earl of Marischal (founder of Marischal College), coat of arms of the city of Aberdeen.

On the other hand, the reference of university emblems to heraldic semiotics is at the same time territorial symbolism, since logos and coats of arms of universities often include elements of the coats of arms of cities and states, including mottos in Latin. Thus, the coat of arms of the University of Nairobi includes elements of both the coat of arms of Kenya and the coat of arms of the capital of Kenya - Nairobi:

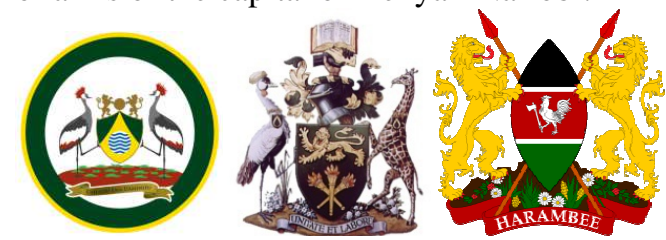

Figure 8. Coat of arms of the city of Nairobi - the capital of Kenya, Coat of arms of the University of Nairobi, Coat of arms of Kenya

In modern versions of university logos, there is no heraldic reference to the territory, but the territorial reference remains in the name of the university (an indication of the city, country, region). This is typical of the overwhelming majority of the names of universities.

For some Russian universities, state symbols prevail in logos, with the help of which universities indicate the status of a Russian and a state university, which in Russia is a sign of reliability of the university and quality of education. State symbols are also typical of universities related to state structures (Ministry of Foreign Affairs, Ministry of Emergency Situations, Ministry of Internal Affairs, government, etc.).

National (ethnic) symbols are far less common in logos. In our material, ethnic symbols in the form of Zilant are present in the logo of the Kazan (Volga Region) Federal University. Zilant - a mythological creature in Tatar folklore - comes from the polymorphic monsters of Central Asia, including the ornithomorphic features of the Semurg (king of birds) and the dogheaded griffin. The dog-headed griffin goes back to the ancient Iranian Senmurv, which combines the features of a serpent, eagle, dog and lion.

Industry symbols are relevant mainly for the logos of specialized universities (medical, agricultural, architectural, etc.).

The study showed that architectural symbols (the main building of the university in the logo) are most typical for domestic universities (about 30-40\%). In the logos of foreign universities, the image of the main university building is rare (10\% for top universities) or is completely absent.

The indication of the foundation year of the university is most typical for Russian universities, however, there is also a tendency towards minimalism: in new versions of logos, the year of foundation disappears (NSU, KFU, SPbPU Peter the Great, TPU, NSTU, Oregon State University, Stanford University, University of Illinois, University of Florida, Johns Hopkins University, Massachusetts Institute of Technology, etc.).
Analysis of the logo symbols did not demonstrate significant differences between top and other foreign and Russian universities. There are no significant differences in symbolism between Russian and foreign universities:

* dominated by the operational, heraldic, nationalstate and industry type of symbolism;

* symbol of a university building is most typical of Russian universities;

* indication of the university foundation year is typical for Russian universities, however, there is also a tendency towards minimalism: in new versions of logos, the year of foundation disappears.

The predominance of national and architectural symbols reflects the identity of the university brand on the basis of territory (location), industry symbols identity in the direction of research, heraldic - in terms of the duration of the university history, its prestige, fundamental nature, tradition, etc.

The shape. Analysis of the shape of the logos showed that the predominant general shape of the logo in the best foreign universities is the form of the heraldic shield $(50 \%)$, while the other universities are dominated by a square $(30 \%)$ and a rectangle $(20 \%)$. Russian universities are also dominated by the form of a heraldic shield (38-42\%), a circle (41\%) and a rectangle (31\%).

Analysis of the logo symbols did not show significant differences between top and other foreign and Russian universities. There are no significant differences in symbolism between Russian and foreign universities:

* the shape of the heraldic shield dominates (38$50 \%$ ), the rest of the universities have a rectangle (20$31 \%)$;

* for foreign universities the frequency form is a square $(30 \%)$, for Russian universities - a circle $(41 \%)$.

Symbolically, a rectangle is the most rational, reliable and correct of all geometric shapes, with the help of which a person has adapted the space for use in everyday life (house, room, table, bed). The square implies hard-to-hold dominance born of an abstract desire for power, while the circle excludes earthly associations due to heavenly symbolism.

Predominance of the heraldic form reflects the identity of the university brand in terms of the duration of the university history, prestige, fundamental nature, tradition, etc.

Thus, the analysis of the university logos showed that there is no significant difference between top universities and universities that are not included in the Top-20, both in Russia and abroad. It should be noted that foreign universities have a more developed branding of products (T-shirts, baseball caps, etc.) with university symbols. In Russia, this advantage is not used enough, while abroad they have already made a separate product niche from branded products of universities.

Most universities do not yet use logos and corporate identity to position themselves in the higher education market. We can only talk about individual initiatives, where the process of using the visual brand identity has become an integral part of the strategic development of the university. 
Evolution of the high school logo. The practice of global brands and branding of transnational companies shows that the heraldic (shields, ribbons, mottos in Latin, fittings, a laurel crown, a wide color palette, a tight visual range, etc.) logo style is actively transforming towards minimalism (brevity, simplicity, clarity, limited color palette, contrast, minimum of elements, a lot of "air", etc.).

Comprehensive analysis of the logos shows that more than $50 \%$ of the logos of foreign universities and more than $40 \%$ of Russian universities are designed in the minimalist style or tend to it. Universities (even those with a long history) strive for a logo that is associated with modernity, dynamism, and innovation. Many universities, trying to preserve the traditional (heraldic) appearance of the logo (emblem), nevertheless try to free it from "unnecessary" elements. Today it is a universal trend in the design of logos for Russian and foreign universities.

IT technologies have given rise to a new trend in creating university logos - generative, "animated" logos: movements and / or changes in the shape of logos (morphing), which are constantly changing, generate a new shape based on a given algorithm of the brand language. Morphing is a visual effect that gives the impression of a smooth transformation of one object into another.

Generative logos are relevant in universities related to design and computer graphics. Examples of such logos are OCAD University logos (Toronto, Canada, university foundation year: 1876) and Design Academy Eindhoven (Eindhoven, Netherlands, academy foundation year: 1947).

OCAD University logo is based on black and white pixel "windows" - modular frames that are filled with variable visual content. The visual content options are the work of students and designers from OCAD University. Every year, the best graduates of the university, within the framework of the basic "window" structure, basing on their work, develop a new set of logos. In fact, this logo format is an archive of the university's brand identities.

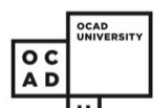

u

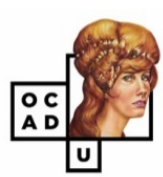

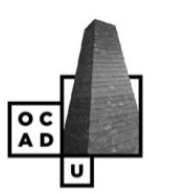

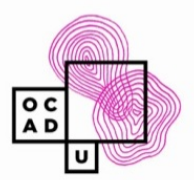

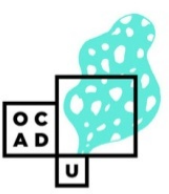

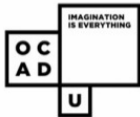

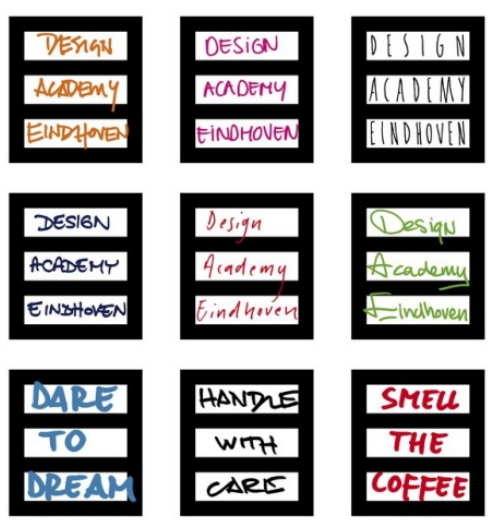

Figure 9. OCAD University and Design Academy Eindhoven logos

The design Academy Eindhoven logo is based on three stripe windows (symbolized by the letter $\mathrm{E}$ Eindhoven), the content and type of font of which is constantly changing. The invariant elements of the logo filling are the words Design Academy Eindhoven, the options are any phrase or combination of the words Kiss the Future, Dare to Dream, Nothing is True. Innovation, mobility, variability, dynamism of the Design Academy Eindhoven $\log$ o is beyond doubt, but its perception is somewhat difficult ("flickering" in the eyes due to the rapid change of words).

Thus, the following trends can be identified in the evolution of Russian and foreign university logos:

* change of heraldic tradition (shields, ribbons, laurel crown, wide color palette, tight visual range, etc.) in logos for minimalism (brevity, accuracy, simplicity of geometric shapes, abundance of empty space, neutral or limited and striving for monochrome colors, which provides good contrast, emphasizes significant elements, etc.);

* simplification of logos in a heraldic style (exemption from individual elements);

* color or symbolic coding of university logos within the invariant base logo;

* formation of a trend for generative, "animated", "live" logos that are constantly changing, generate a new form based on a given algorithm of the brand language.

When building relationships with various target audiences of higher education, graphic logo design acts as a tool that conceptualizes visual content and constructs an image in the landscape of visual communication.

\section{References}

1. A. Eisingerich, G. Rubera, J. Int. Mark., 18(2), 64-79 (2010)

2. B. Hetet, C.-L. Ackermann, J.-P. Mathieu, J. Prod. Brand. Manag., 29(5), 569-581. (2019)

3. P. Rodkin, What is visual communication? Retrieved from: www.prdesign.ru/text/2010/visualcommunication 
4. A. Berger, Seeing is believing. Introduction to Visual Communication (Publishing House Williams, 2005).

5. Bullard D.B. Academic Capitalism in the Social Sciences: Faculty Responses to the Entrepreneurial University: Ph.D. diss. (University of South Florida, 2007.)

6. B. Vaneken, Brand Aid (Peter, 2005).

7. V. Domnin, Branding: New Technologies in Russia. 2nd ed. (Peter, 2004).

8. A. Buzinova, Mediascope, 4 (2013).

9. P. Demin University Management: Practice and Analysis, 22(6) (2018). 